\title{
O Ciclo do Grande Hotel da Beira: OS DOCUMENTÁRIOS GRANDE HOTEL, DE LotTe Stoops; Grande Hotel, de ANABEla SAINT-MAURICE; HósPedes da NOITE, DE LicínIO AZEVEDO E AMANHECER A ANDAR, DE SÍlLIA FIRMINO ${ }^{1}$
}

Giulia Spinuzza ${ }^{2}$

Resumo: O objectivo deste artigo é analisar quatro documentários sobre o Grande Hotel da Beira, em Moçambique. Nesta pesquisa iremos focar as representações cinematográficas do Grande Hotel realizadas no pós-independência. Aprofundaremos as perspectivas que evidenciam o tecido pluricultural da cidade da Beira, fruto das conexões criadas através do Oceano Índico, e problematizaremos a relação entre o presente pós-colonial e o passado colonial. No final do texto iremos abordar também o último livro de João Paulo Borges Coelho (2017), Ponta Gea, cujo título se refere ao bairro beirense no qual está localizado o Grande Hotel.

Palavras-chave: Grande Hotel; documentários; Oceano Índico.

Neste ensaio propomos analisar quatro documentários sobre o Grande Hotel da Beira em Moçambique. Construído durante a época colonial e inaugurado em 1955, de frente para o Oceano Índico, esse hotel de dimensões grandiosas e com uma fachada curvilínea modernista entrou rapidamente em decadência e foi abandonado. O Grande Hotel,

1 Este trabalho é financiado por fundos nacionais através da FCT - Fundação para a Ciência e a Tecnologia, I.P., no âmbito do Projecto NILUS - Narrativas do Oceano Índico no Espaço Lusófono (PTDC/CPC-ELT/4868/2014).

2 Bolseira de investigação do Projeto NILUS - Narrativas do Oceano Índico no Espaço Lusófono (PTDC/CPC-ELT/4868/2014), CeSA/CSG, ISEG, Universidade de Lisboa, Portugal: giuliaspin@yahoo.it. 
que representava a vida glamorosa de uma localidade turística durante a época colonial tardia, foi objecto da propaganda colonial, que propagava a ideia do Éden tropical frente ao Índico, associada a esse local paradisíaco. Hoje esse espaço é habitado por uma multidão de pessoas que luta a cada dia pela própria sobrevivência e dignidade.

Neste ensaio iremos analisar um documentário moçambicano e três documentários internacionais sobre o hotel, realizados após a independência do país (25 de junho de 1975): Hóspedes da noite, de Licínio Azevedo (Moçambique, 2007); Grande Hotel, de Lotte Stoops (Bélgica, 2010); Grande Hotel, de Anabela Saint-Maurice (Portugal, 2007) e Amanhecer a andar, de Sílvia Firmino (Portugal, 2012), sendo este último abordado muito brevemente aqui.

Tendo em conta os documentários mencionados, o nosso objectivo é aprofundar as seguintes problemáticas: a clivagem entre o passado colonial e o pós-independência; o desenvolvimento e a decadência das rotas comerciais e marítimas da Beira; o Grande Hotel enquanto imagem de luxo para turistas estrangeiros; e o Grande Hotel no contexto pluricultural da cidade da Beira, fruto de múltiplos processos migratórios e comerciais através do Oceano Índico. Por último, iremos analisar alguns capítulos do livro Ponta Gea (2017), o mais recente romance de João Paulo Borges Coelho (doravante JPBC).

$\mathrm{Na}$ realidade, o autor moçambicano passou a própria infância e adolescência na cidade da Beira, tendo crescido em Ponta Gea, um bairro constituído por um conjunto de casas unifamiliares debruçadas frente ao Índico e no qual está localizado o Grande Hotel. Então, iremos comparar alguns dos capítulos desse livro - constituído por memórias geográficas da cidade da Beira durante o período colonial - com os documentários sobre o hotel.

A partir dessas obras cinematográficas e literárias propomos enquadrar o Grande Hotel e a cidade da Beira na rede marítima, comercial e humana do Oceano Índico. Nesse sentido, interessa-nos sobretudo repensar essa cidade costeira enquanto porto do Índico e enquadrá-la no contexto do litoral e no âmbito de múltiplos processos migratórios que interessa(ra)m ao Oriente e a Moçambique. Porque, como afirma Edward Alpers (2015), as relações comerciais entrelaçadas nessa rede económica do Oceano Î́ndico criaram também relações humanas. Esse aspecto, como veremos, emerge principalmente no documentário de Anabela SaintMaurice (GRANDE HOTEL, 2007). 
Paralelamente, propomos uma leitura diacrónica que irá focar o luxo e a sucessiva decadência dessa estrutura hoteleira, tendo em conta também a história da cidade da Beira. Na verdade, durante as décadas de 1950 e 1960 várias reportagens cinematográficas produzidas no contexto da propaganda colonial evocavam a imagem de Éden tropical associada a essa cidade moderna, rica e cosmopolita, que era frequentada por turistas das então colónias limítrofes inglesas. Todavia, a pouca rentabilidade do hotel assinalou o começo da sua decadência, que se tornou ainda mais evidente com o longo período de guerras que abalou o país e com a interrupção das rotas comerciais com os territórios confinantes, o que levou a uma drástica diminuição da actividade do caminho-de-ferro e do porto da Beira, como veremos mais adiante.

Nesse sentido, verificamos que os documentários sobre o Grande Hotel ao evocarem o passado dele (e da cidade da Beira), bem como seus problemas actuais, problematizam várias questões de carácter histórico, político, social e cultural. A obra de Lotte Stoops, como veremos, é a que mais dialoga com o passado colonial, enquanto o documentário de Licínio Azevedo oferece um diálogo com o passado a partir do ponto de vista "interno" de dois ex-empregados do hotel, que relembram a então luxuosa estrutura. Dessa forma, as memórias do passado colonial que emergem nesses dois documentários apresentam múltiplas perspectivas sobre a história de decadência do hotel.

O Grande Hotel entrou em decadência já na época colonial, poucos anos depois de sua abertura, ${ }^{3}$ antecipando de certa forma a decadência da cidade da Beira, causada pela diminuição do fluxo das rotas comerciais e marítimas que passavam por essa cidade costeira devido à particular conjuntura histórica, nacional e internacional, e às relações com os territórios confinantes. Referimo-nos especialmente à interrupção da ligação entre a então Rodésia ${ }^{4}$ (e o interior da África) e o Oceano Índico através do caminho-de-ferro e do porto da Beira. Como notam os autores de um estudo sobre essa cidade, podemos dizer que durante a época colonial a Beira se tornou "o porto natural da economicamente emergente Rodésia, o que atrai a si capitais e cidadãos britânicos e sul-africanos que investem no caminho-de-ferro entre a Beira e Harare" (FERNANDES;

$3 \mathrm{O}$ Hotel, no plano inicial, teria que incluir um casino, que não foi autorizado. Isso contribuiu para a não rentabilidade da enorme estrutura turística.

4 Actualmente Zimbabwe. 
MEALHA; MENDES, 2016, p. 157). Assim, a cidade da Beira representava um local estratégico de ligação entre o Índico e o hinterland africano.

Dessa forma, durante a época colonial, o porto e o caminho-de-ferro permitiram o florescimento da cidade e houve um grande investimento financeiro quer na arquitectura, quer na organização urbanística. Destaque-se a esse propósito a estação dos comboios e o Grande Hotel, construções monumentais que se enquadram no movimento da arquitectura modernista. Esses edifícios representam o exemplo da concretização de ideias modernistas na África tropical, que se estendem a toda a planificação urbanística do centro da cidade colonial5 (FERNANDES; MEALHA; MENDES, 2016).

Para além desses exemplos de arquitectura, a partir dos anos 1950 desenvolveu-se um projecto urbanístico de cidades-jardins, que procurava inserir na cidade da Beira vários espaços verdes para o lazer; tal desenho interessou no específico aos bairros de Macuti, Palmeira e Ponta Gea (MALOA, 2016), este último, como já dissemos, onde se situa o Grande Hotel. Porém, como evidenciam vários estudos, tal renovação da cidade fez-se às custas de mão de obra "segregada e barata" de negros, indianos e chineses ${ }^{6}$ que provinham do outro lado do Índico (MALOA, 2016, p. 181).

Outro setor-chave para o desenvolvimento da cidade foi o turismo. Com efeito, o crescimento económico e comercial da cidade na década de 1950 e a criação de cada vez mais equipamentos dedicados ao lazer (hotéis, restaurantes, cinema, boîtes etc.) permitiram que a Beira se tornasse uma "instância de veraneio para os turistas provenientes da África do Sul, Rodésia e Malawi” (FERNANDES; MEALHA; MENDES, 2016, p. 160). Note-se a esse propósito que existem algumas reportagens cinematográficas, sobretudo do período tardo-colonial, que publicitam as praias e actividades balneares e marítimas dessa cidade (pesca, sky-surf etc.).

Na realidade, segundo emerge nos dados do Boletim do Ultramar (apud MALOA, 2016), o número de visitantes na cidade da Beira passou de 2.000 em 1942 a 32.513 em 1956. Os turistas concentravam-se principalmente

\footnotetext{
5 Excluindo, então, os bairros onde moravam os habitantes locais negros.

6 Como nota Medeiros (2007, p. 7), "todos os imigrantes, contratados ou não, que vieram da Ásia para Moçambique eram originários dos distritos de Shunde (em cantonês lê-se Sontak), Toishan (ou Toi San) e de Zhongshan (ou Zhong Shan), que é o mais próximo de Macau. Todos estes distritos pertencem à província de Guandong (Guan Dong, Kuang Tong ou Kwantung), cuja capital é Cantão. Em todas estas regiões o idioma principal é o cantonês (alguns dizem cantonense), que possui vários dialectos”.
} 
nos bairros de Macuti e Ponta Gea (MALOA, 2016), e obviamente a esse crescimento do turismo correspondia, como vimos, também uma proliferação de hotéis, boates e dancings, localizados sobretudo na área adjacente à costa (FERNANDES; MEALHA; MENDES, 2016).

Assim, o Grande Hotel surgiu no contexto desse desenvolvimento urbanístico, como exemplo da liberdade criativa que os arquitetos não podiam ter na metrópole e com um vocabulário ligado sobretudo a certo modernismo arquitectónico brasileiro (FERNANDES; MEALHA; MENDES, 2016). Em suma, o hotel, com piscina olímpica, restaurante e seletiva boate, satisfazia em pleno às necessidades dos ricos turistas estrangeiros e da elite beirense.

No entanto, se por um lado houve um desenvolvimento moderno e "cosmopolita" da cidade, por outro lado os negros eram segregados nos bairros de caniço, ${ }^{7}$ nas margens do núcleo urbano visitado por turistas principalmente anglófonos (dos estados limítrofes). No centro da cidade, para além dos portugueses, habitavam também indianos e chineses ${ }^{8}$ (mais abastados) vindos do outro lado do Índico, segundo emerge tanto no documentário de Anabela de Saint-Maurice, quanto no texto de JPBC. $\mathrm{Na}$ verdade, como afirma também Maloa (2016), os negros habitavam sobretudo no bairro da Manga, enquanto os europeus, chineses e indianos mais abastados habitavam moradias unifamiliares nos bairros de Ponta Gea, Palmeira e Macuti (mais próximos do Oceano Índico). Assim, existia uma clara distinção urbanística entre as zonas de habitação dos negros e a outra parte da cidade.

Para além disso, como vem à tona no livro de JPBC, havia também uma delimitação, definida pela própria geografia da cidade, com os bairros turísticos e centrais mais próximos do oceano e a zona dedicada ao comércio no interior do promontório. É o que podemos ler no capítulo de Ponta Gea "Dragão Oriental”, no qual o protagonista se desloca a pé até o Maquinino, um bairro "periférico de comércio e armazéns" (2017, p. 225) localizado além do rio Chiveve, do lado oposto da Baixa beirense.

Os aspectos mencionados são extremamente relevantes para entender a localização do Grande Hotel no contexto geográfico da Beira.

\footnotetext{
7 O bairro de caniço, constituído por habitações precárias, abrangia frequentemente uma zona suburbana e contrapunha-se à "cidade de cimento", caracterizada por habitações e prédios modernos no centro da cidade.

8 “Dos 2.098 'amarelos' recenseados em Moçambique em 1960, 1.136 eram homens e 962 mulheres. Do total na colónia, 1.027 indivíduos $(548 \mathrm{H})$ habitavam no distrito de Manica e Sofala, dos quais 968 no concelho da Beira" (MEDEIROS, 2013, p. 45).
} 
Todavia, antes de passarmos à análise das obras propostas, gostaríamos de mencionar o documentário Moçambique: no outro lado do tempo (1996) de Luís Beja, realizado em 1996, o qual utiliza imagens da época tardo-colonial e dedica cerca de cinco minutos à Beira. Esse documentário foca o desenvolvimento comercial e económico da cidade, com o porto e o caminho-de-ferro, a circulação de indivíduos, o trânsito da cidade, a estação dos autocarros e a produção industrial do sisal para as cordas.

Essa obra oferece, com um olhar melancólico e saudosista, a imagem do "paraíso [colonial] perdido", 9 que não é feito apenas de praias, mas é também rico em termos económicos e comerciais. A descrição da cidade começa com a evocação do "maior porto da África oriental", um lugar estratégico para os navios nas rotas do Índico. A letra da canção que acompanha as últimas imagens da Beira com a actividade do porto relembram a relação amorosa (não correspondida) com essa cidade: "Ó Beira não és nem serás toda minha por muito que eu seja capaz de te amar. Ó Beira por muito que eu queira, o amor não me pode ajudar, [...] não negues ó Beira que és noiva do mar" (MOÇAMBIQUE, 1996, grifos nossos). Assim, enquanto a cidade de Lourenço Marques era apelidada de "feiticeira", a cidade da Beira é chamada de "noiva do mar", sublinhando então a ligação desta cidade com o Oceano Índico.

Esse documentário de produção portuguesa utiliza imagens da época colonial (da década de 1960 e princípios de 1970), com uma voz narradora que percorre a geografia moçambicana. Sem oferecer uma reflexão crítica sobre as multifacetadas e complexas dinâmicas coloniais, essa obra enaltece o desenvolvimento económico, agrícola e industrial das maiores cidades e regiões moçambicanas antes da independência do país, ${ }^{10}$ sublinhando positivamente a ação colonizadora dos portugueses. $\mathrm{O}$ aspecto mais problemático é o facto de este documentário perpetuar a ideia de colonização enquanto missão civilizadora, enaltecendo a capacidade de perfeita convivência e mistura dos portugueses com as populações locais (em chave lusotropicalista), sem problematizar as complexas dinâmicas históricas e sociais que têm caracterizado o processo colonial em Moçambique (e não só). Basta pensar, a esse propósito, nas

\footnotetext{
9 Essa ideia é reforçada pela trilha sonora, constituída por várias canções dedicadas à excolónia, as quais incrementam o lado melancólico e saudosista do documentário.

10 Note-se que, na dedicatória que antecede as imagens desse documentário, podemos ler que a obra é dedicada "a todos os que nasceram em Moçambique e à Pátria moçambicana que conquistou a sua justa independência” (MOÇAMBIQUE, 1996).
} 
palavras iniciais do narrador: "Nenhum povo da colonização europeia da África Negra se misturou e viveu tão naturalmente ao nível humano como o português" (MOÇAMBIQUE, 1996)."

Então, esse documentário, realizado dois anos antes da Expo'98, contribuiu para fortalecer o falso mito das colónias como locais paradisíacos onde se vivia em plena paz e harmonia entre povos, evocando a ideia do colonialismo enquanto processo de convivência e troca cultural, e retomando também a perspectiva lusotropicalista, em evidente contraste com uma realidade dominada por barreiras raciais e por profundas problemáticas económicas e sociais estabelecidas pelo próprio sistema colonial.

Pareceu-nos oportuno evocar esse documentário para estabelecer uma ligação, se bem que problemática, com a obra de Lotte Stoops (GRANDE HOTEL, 2010), que problematiza, em parte, essa perspectiva saudosista e melancólica através das recordações de alguns retornados portugueses. Na verdade, esse documentário privilegia uma perspectiva diacrónica, sobrepondo à narrativa oral (através das voice-overs) as imagens do passado (fotografias ou curtos trechos cinematográficos do período colonial) e do presente. Para além disso, há um contínuo diálogo entre o esplendor do passado e a miséria do presente; de facto, através da voice-over o documentário focaliza a perspectiva de quem, como Berta, uma das protagonistas do documentário de Stoops, teve que abandonar esse "Éden" tropical que ela identificava com a "própria" casa.

Ao contrário, no documentário Hóspedes da noite (2007), de Licínio Azevedo, há uma quase total ausência de voice-over e imagens do passado, sendo que as únicas memórias do hotel são as dos ex-empregados. Dessa forma, a obra desse diretor privilegia duas perspectivas: por um lado, a história e estórias dos moradores atuais do Grande Hotel e, por outro, a narração do passado glamoroso do hotel, feita por dois antigos empregados que deambulam pelos escombros da estrutura, relembrando um tempo e um espaço que já não coincidem com o daquele momento.

Essas duas dimensões se completam e se sobrepõem: a memória do passado evocada verbalmente pelos dois ex-empregados sobrepõe-se às imagens do presente. Então, as vozes dos antigos empregados são elementos de conexão entre duas épocas históricas e representam uma memória colonial quase totalmente apagada pelos escombros atuais.

11 Tudo isso utilizando imagens de uma época em que já tinha começado a guerra colonial. 
No entanto, através das lembranças dos empregados, os fantasmas do passado parecem coabitar com os novos inquilinos do hotel. Note-se a esse propósito que no capítulo sobre o Grande Hotel, do livro Ponta Gea (COELHO, 2017), o autor utiliza a mesma estratégia narrativa, sobrepondo as lembranças de infância no hotel ao tempo presente, como veremos mais adiante.

Voltandoà obra de Lotte Stoops (GRANDE HOTEL, 2010), verificamos que há uma alternância constante entre o presente e o passado, ou seja, entre os breves episódios sobre o quotidiano dos moradores do hotel e as lembranças evocadas pelas voice-overs através dos depoimentos de pessoas que não estão fisicamente presentes na cena representada. Essas vozes, ao evocarem a história do hotel, repercorrem também a história do país, desde as luxuosas festas e celebrações que o Hotel acolheu (como o casamento de Maria Isabel Jorge Jardim - Patucha Jardim, filha de Jorge Jardim), o período de quartel militar, na época da guerra civil, e, actualmente, a situação de abandono do edifício, ocupado por centenas de pessoas que chegaram com a guerra, a fome, as cheias e a pobreza.

Apesar de não estarem identificadas, as voice-overs apresentam perspectivas diferentes que focam vários períodos cronológicos, como é o caso dos portugueses retornados que relembram o hotel e a cidade da Beira durante a época colonial (incluindo a própria Patucha Jardim) ou dos moçambicanos que vivenciaram o conturbado período tardo-colonial e o pós-independência. Podemos então dizer que esses múltiplos fragmentos do passado, feitos de vozes e imagens, constituem várias camadas sobrepostas que problematizam uma visão unívoca sobre o período colonial e pós-colonial. Em particular, as voice-overs, que por vezes contrastam com as imagens apresentadas, permitem sobrepor, segundo afirma a realizadora, dois tempos cronológicos e múltiplas perspectivas: "I wanted to superimpose an auditory narrative of the past (by different characters who lived that past) on the visual narrative of the present" (STOOPS, [s.d.]). ${ }^{12}$ Podemos então dizer que a narrativa do documentário é constituída por dois planos paralelos: por um lado, as narrativas das personagens presentes na cena e, por outro lado, as narrativas orais das voice-overs.

12 "Queria sobrepor uma narrativa auditiva do passado (por diferentes personagens que viveram esse passado) a uma narrativa visual do presente”. Todas as traduções de citações são nossas. 
Esse aspecto é bastante evidente desde o começo do filme, através de um longo plano geral do hotel, com um movimento panorâmico da câmara à volta da arquitectura curvilínea, que ressalta ainda mais a extensão e grandiosidade da estrutura já em decadência, completada a cena pela narração das voice-overs. Como afirma a realizadora:

The Grande Hotel is pictured with long shots in order to give an overview and to emphasize its grandness. These long shot have the aesthetics of an invitation; we use P.O.V's [point of views] typical of promotional films in the era the hotel was built. Contrasting with this is the intimacy to the characters. (STOOPS, [s.d.] $)^{13}$

As imagens do hotel no presente e no passado são acompanhadas pelas lembranças de Berta, juntamente com outros depoimentos que definem a obra como o "produto colonial de um louco" ou "um elefante branco, um projecto megalómano” (GRANDE HOTEL, 2010). Para além disso, as vozes revelam uma rigorosa seleção à entrada do hotel durante a época colonial, visto que "não era qualquer moçambicano que entrava ali" (GRANDE HOTEL, 2010).

Nesse sentido, podemos dizer que o documentário não deixa de apresentar múltiplas perspectivas sobre o Grande Hotel, sobretudo no final da obra: por um lado, ouvimos os sonhos e ambições dos inquilinos do hotel, que não perdem a esperança no futuro e demonstram uma grande capacidade de resiliência, e, por outro lado, ouvimos as vozes de quem, como Berta, vive no sonho do passado. No entanto, o documentário não encontra uma forma eficaz de conciliar tais perspectivas.

Uma problemática relacionada com esse aspecto tem a ver com as opções de montagem e edição da realizadora, que ao recorrer ostensivamente às voice-overs constrói vários planos narrativos, criando por vezes uma "cacofonia" que não permite identificar os intervenientes, inviabilizando assim a contextualização identitária dos oradores e seus depoimentos.

Berta, que relembra o hotel e a sua vida, é a única exceção, porque o documentário reconstrói sua história e vivência. Ela é uma senhora idosa que viveu na Beira durante a época colonial e que reside em Portugal há 33 anos. As suas lembranças são, ao nosso ver, as mais problemáticas, por

13 "O Grande Hotel é filmado em planos abertos para dar uma visão geral e enfatizar sua grandeza. Esteticamente esses planos abertos representam um convite; utilizamos pontos de vista típicos dos filmes promocionais da época em que o hotel foi construído. Contrasta com isto a abordagem íntima às personagens." 
questionarem a pertença identitária, a memória colonial e a sua relação com o tempo presente, com toques saudosistas do passado. Leiam-se a esse propósito algumas das suas afirmações:14 "Vivíamos no paraíso, e não o sabíamos", "deixei o meu coração lá", "tenho a impressão de estar aqui de férias" (GRANDE HOTEL, 2010). ${ }^{15}$ Com essas palavras, Berta questiona sua identificação identitária com Portugal e evoca a imagem do paraíso perdido, no entanto essa memória se articula de forma problemática com as imagens do hotel no presente. Que tipo de diálogo se estabelece entre Berta e os moradores do hotel? As perspectivas que emergem desse documentário parecem não dialogarem entre si, porque enquanto Berta vive apenas no passado, os moradores do hotel, ocupados com a sua luta diária, vivem pensando no porvir.

Para além disso, por vezes as recordações de Berta aproximamse do imaginário turístico exótico proposto em várias produções cinematográficas da época colonial (como é o caso do supracitado documentário de Luís Beja). Cria-se assim o risco de perpetuar a narrativa do Éden tropical, de um paraíso perdido que de certa forma retoma a imagem construída no período tardo-colonial: uma cidade próspera, pacífica e cosmopolita com uma imponente actividade comercial e marítima. Nesse sentido, as recordações de Berta contrastam com uma realidade que já não existe e que, de certa forma, nunca existiu. Então, verificamos que o documentário parece não questionar de forma explícita a visão da realidade colonial beirense evocada por Berta.

Por último, a relação dela com o hotel e a cidade da Beira torna-se mais problemática pela reivindicação da pertença identitária que a liga àquele lugar e especialmente ao Oceano Índico. Essa ideia é reforçada pela realizadora, que associa várias vezes a imagem de Berta e a voz dela ao mar e ao Oceano Î́ndico. ${ }^{16}$ A própria Berta reivindica essa ligação especial com o Índico, como evidenciam as palavras que fecham o documentário:

\footnotetext{
14 No documentário, a voice-over de Berta é em inglês, no entanto optamos por transcrever os subtítulos em português. Note-se que não é claro se a escolha do inglês (todas as outras voice-overs são em português) foi uma opção da realizadora ou se o inglês é a língua materna de Berta.

15 "We lived in paradise and we didn't know"; "What was worse is that what I left was my heart"; "I have the impression of being here on vacation".

16 A propósito dessa questão, agradeço a intervenção da professora Ute Fendler (University of Bayreuth), que ressalvou esse aspecto, no encontro que teve lugar em julho de 2017, em Lisboa, no âmbito do Projecto NILUS-Narrativas do Oceano Índico no Espaço Lusófono, financiado pela Fundação para a Ciência e a Tecnologia.
} 
“Os portugueses têm o seu próprio mar, não é mal, mas não é o meu” (GRANDE, 2010), ${ }^{17}$ enquanto no caso dos moradores do hotel nunca é sugerida, nem visualmente, nem ao nível de narração, a ligação ao Índico. Note-se também que, no final do documentário, a imagem do hotel no período colonial retoma os fotogramas iniciais com o som e a imagem do mar da Beira: nesse lapso cinematográfico, nada sabemos sobre o mar dos "outros".

Para além disso, Berta declara mais de uma vez que vêa sua estadia em Portugal como uma passagem, como se estivesse de férias num lugar que não lhe pertence, é hóspede de uma terra que não identifica com a própria casa. Diferentemente do documentário que vimos comentando, no de Licínio Azevedo (HÓSPEDES, 2007) esse estado de transição interessa aos moradores do hotel, que são chamados, como sugere o título, "hóspedes da noite". Assim, torna-se mais evidente que as duas obras, apesar de retratar o mesmo espaço, apresentam pontos de vista e preocupações diferentes.

À semelhança da obra de Lotte Stoops (GRANDE HOTEL, 2010), também o documentário de Anabela Saint-Maurice (GRANDE HOTEL, 2007) começa com a evocação do passado, através de imagens da época colonial que retratam banhistas e turistas a aproveitarem as férias na Beira. No entanto, a atenção da realizadora portuguesa concentra-se no tecido cultural e social da cidade, evidenciando as múltiplas dinâmicas históricas e sociais geradas pelas interconexões no espaço do Oceano Índico.

Esse documentário, que enquadra o hotel no contexto urbano da Beira, foca-se no tempo presente. Nessa obra emerge sobretudo a imagem dessa cidade enquanto espaço feito de cruzamentos transnacionais, por meio da presença de múltiplas culturas e religiões que transita(ra)m entre o Oriente e Moçambique através do Oceano Índico, como veremos mais adiante.

Logo no começo do documentário, após as imagens da época colonial, é apresentado o depoimento de Maria Isabel "Patucha" Jardim, filha de Jorge Jardim, empresário e homem do regime colonial muito influente nessa cidade. Ela casou-se com um oficial da Marinha Portuguesa no Grande Hotel, com uma cerimónia grandiosa. Quando questionada pela realizadora sobre a existência da segregação racial na cidade de betão (cidade de cimento), Patucha Jardim num primeiro momento confirma

17 “The Portuguese people have got their own sea, it's not bad, but it's not mine". 
tal segregação, mas depois se corrige e recusa a definição de "cidade dos brancos", devido à presença de indianos e chineses que viviam no centro urbano, apesar de admitir que os negros viviam nas margens desse núcleo central. Com efeito, a maioria dos negros vivia em bairros periféricos, enquanto o centro da cidade foi gradualmente abandonado após a independência do país, deixando na memória dos retornados a imagem de um espaço mitificado, um Éden tropical, um paraíso perdido no tempo e no espaço.

O documentário ressalva também o desenvolvimento económico durante a época colonial, devido à já mencionada ligação entre o litoral beirense e a fronteira da Rodésia e do Malawi, através dos caminhos-de-ferro e do porto, este que, na altura, servia também para os navios de passageiros. Considerado o bom desenvolvimento da cidade, apostouse então no turismo, por meio da projectação do Grande Hotel pela Companhia de Moçambique e de outras estruturas de lazer e hospedagem. No documentário a passagem súbita da época colonial para a actual é feita através da intervenção de Francisco de Castro, o último arquiteto que trabalhou na edificação do hotel e que, aos 83 anos, numa "torna-viagem" que o leva de Portugal a Moçambique, vai visitar a cidade da Beira e o hotel.

Após ter mostrado o interior do antigo hotel e a vida dos seus moradores, a realizadora refere a decadência da cidade, que sofreu com a guerra no imediato pós-independência. Depois da destruição dos caminhos-de-ferro e da interrupção das relações com o regime segregacionista dos estados confinantes, a actividade económica da cidade reduziu-se à pesca e à exportação do camarão. Em suma, a primeira parte desse documentário enquadra o contexto económico e histórico que levou ao surgimento (e à sucessiva decadência) do Grande Hotel.

É então que a realizadora entra na actual cidade da Beira, alargando o olhar à volta do Grande Hotel. Essa segunda parte oferece um olhar sobre a cidade ali presente, ou seja, contextualiza o hotel no tecido económico, social e cultural da Beira nos dias de hoje. A realizadora foca também os problemas das cheias que pontualmente afligem a cidade, a questão da habitação, a reabilitação das linhas de ferro etc. E, a partir da estação dos comboios, projectada por Francisco de Castro (em coautoria com outros dois arquitectos), começa uma outra viagem através das diferentes comunidades que habitam a Beira. Quem acompanha a realizadora é o arquiteto de ascendência chinesa, Marcos Pan (cuja família é natural do 
Cantão), ${ }^{18}$ encarregado da reabilitação da Estação dos Comboios. Pan mostra-nos que as comunidades indiana e chinesa, que gerem sobretudo o sector comercial, estão ainda bem presentes na Beira.

A realizadora acompanha o arquitecto, nascido em Moçambique, de volta à sua casa natal. Pan, descendente da primeira comunidade chinesa que se fixou na cidade, conta a história da família, mostra as fotos dos avós, o dicionário chinês-português e explica o funcionamento da antiga "casa-loja", constituída na parte da frente por uma mercearia e, na parte de trás, pelas habitações familiares. Tal conformação era bastante típica entre os comerciantes chineses, que viviam na parte traseira das próprias lojas, todavia Pan desenhou para si um outro destino profissional e não envergou pela actividade comercial.

O avô de Pan saiu ainda jovem do Cantão para vir de barco para a Beira trabalhar na construção (como vimos, toda a renovação e saneamento da cidade foi feita recorrendo à mão de obra de negros, chineses e indianos desde finais do século XIX). Actualmente, parte da família de Pan vive em Portugal, como nota a realizadora, porque, com a Independência do país, muitos chineses que tinham vindo a Moçambique foram para Portugal ou Macau.

Tendo em conta a narração da vivência familiar de Pan e considerando alguns dos estudos disponíveis nesse âmbito, como os de Eduardo Medeiros (2007), que publicou vários ensaios sobre os sino-moçambicanos, verificamos que a comunidade chinesa chegou à cidade da Beira, então administrada pela Companhia de Moçambique, nos finais do século XIX, porque vários coolies $^{19}$ chineses foram contratados para a construção do porto e do caminho-de-ferro. Devido a uma cada vez mais crescente diversificação ocupacional, em meados do século XX muitos chineses começavam a trabalhar no comércio e indústria na cidade de cimento (MEDEIROS, 2007, p. 14), sendo que mais tarde "a maioria dos filhos sinoasiáticos e sino-chineses [sic] escolarizados passou a trabalhar na função pública, nos escritórios de profissionais liberais: arquitetos, engenheiros, médicos etc.", como é o caso de Marcos Pan.

O arquitecto acompanha Saint-Maurice (GRANDE HOTEL, 2007) ora no bairro onde vários comerciantes de diferentes origens exercem suas funções. Assim a história do arquiteto de origem chinesa, bem como

18 Ver nota 3 .

19 Trabalhadores de origem asiática (China, Índia etc.) contratados por um valor muito baixo no contexto transnacional do Oceano Î́ndico. 
as entrevistas a vários comerciantes de origem indiana, revelam o tecido pluricultural e plurirreligioso dessa cidade.

O olhar da realizadora mostra não apenas a actividade comercial dos indianos no bairro do Maquinino, mas também a intervenção em âmbito religioso e social dessas pessoas e das suas comunidades religiosas. Por exemplo, o alfaiate Nitino, de origem indiana, é também presidente da comunidade hindu da Beira.

Ismail Mahomed, cujo pai chegou à cidade da Beira nos anos 1920, trabalha no ramo alimentar. Ele optou por sair de Moçambique durante a guerra civil, residiu em Portugal durante dez anos, mas a incapacidade de se adaptar à vida frenética da capital lusitana fez com que decidisse voltar para a Beira. Actualmente, é vice-presidente da comunidade muçulmana de Sofala. Segundo refere Saint-Maurice (GRANDE HOTEL, 2007), a comunidade muçulmana da Beira conta com 6.00o pessoas e desenvolve muitos projectos na área da educação e habitação. É graças a um desses projectos que parte da comunidade do Grande Hotel foi realojada num novo bairro (financiado por Dubai), onde funciona uma madrassa (escola islâmica de ensino religioso).

Nesse sentido, o documentário de Anabela Saint-Maurice acaba por ser um retrato não apenas do hotel, mas também da cidade da Beira, mostrando a ligação entre os dois mundos, como é o caso do envolvimento da associação muçulmana de Sofala no processo de realojamento de uma parte dos habitantes do hotel, recorrendo a financiamento internacional. Assim, as comunidades religiosas substituem, pelo menos parcialmente, o Estado, incapaz de solucionar o problema da habitação. Todavia, no final do documentário a realizadora acompanha a visita ao hotel do Presidente do Conselho Municipal da Beira, Daviz Simango (MDM - Movimento Democrático de Moçambique). Mas como emerge no conto "Casas de ferro", do livro Índicos indícios - Setentrião (COELHO, 2005), por vezes as instituições e os políticos ficam num impasse, não conseguindo solucionar os problemas concretos do "Povo".

Num último olhar à volta da cidade, as imagens do documentário de Saint-Maurice mostram que grande parte da população vive nas margens do centro, em casas tradicionais. Na opinião da cineasta, o desenvolvimento da cidade é uma aposta que deve ser feita a partir da reabilitação dos caminhos-de-ferro e do porto, sendo sublinhada mais uma vez a importância dessa cidade, localizada no elo que liga o Índico e o interior do território moçambicano (e africano). 
Nesse sentido, o documentário de Saint-Maurice é entre todos o que mais enquadra o hotel na dinâmica económica, social e política da Beira e do litoral. Como vimos, essa importante cidade portuária desenvolveu uma rede de comboios entre o porto e o interior, no chamado "corredor da Beira”, que ligava a então Rodésia ao Oceano Índico. Paralelamente a essa rede comercial em direcção ao interior, houve também uma rede que se estendia através do Oceano Índico e que punha em contacto o porto da Beira com várias regiões orientais. ${ }^{20}$

Então, o documentário evidencia a presença de várias comunidades orientais que constituem parte do tecido social da cidade (como é o caso dos indianos e chineses), resultado da conectividade do Oceano Índico, segundo emerge nas entrevistas ao arquitecto chinês e aos comerciantes indianos. Nesse sentido, são interessantes as histórias familiares (e a sua reconstrução genealógica), ${ }^{21}$ que nos permitem entender as migrações entre a China, a Índia e Moçambique (e, por vezes, entre Moçambique e Portugal). ${ }^{22}$ Assim, sobressai-se a imagem de uma cidade transnacional, um porto do Índico fruto das múltiplas interconexões comerciais, económicas, religiosas, familiares e culturais, criadas à volta desse espaço movediço.

O documentário de Sílvia Firmino, Amanhecer a andar (2012), também sobre o Grande Hotel, não foca tanto as interconexões entre o hotel e a cidade, à excepção do aspecto religioso. Na realidade, esse documentário ressalva sobretudo a tentativa dos seus moradores de sair da pobreza, como emerge do título do documentário, o qual retoma a expressão de um dos entrevistados: é necessário "amanhecer a andar" para ser produtivos e tentar mudar a própria condição económica. Assim, a obra de Sílvia Firmino foca sobretudo as "pequenas" histórias de resistência e resiliência dos moradores do hotel, como é o caso de Augusto, que cuida da escola

20 Note-se, todavia, que essa rede comercial e migratória não existiu apenas no período colonial, mas, como demonstram numerosos estúdios, também no período pré-colonial. $21 \mathrm{O}$ professor Jeremy Prestholdt (U. California, San Diego), no podcast Indian Ocean Africa-Icons, Commodities, Mobility (Africa Online Digital Library, episode 111, disponível em: <http://afripod.aodl.org/2017/05/afripod-111/>), analisa os bens, as mercadorias, a cultura e o "imaginário transnacional" da África Oriental, mencionando também a importância das relações genealógicas no contexto transnacional do Índico.

22 Verificamos, por exemplo, que a emigração para Portugal após a Independência de Moçambique pode ser vista como uma nova travessia, por vezes acompanhada por uma “contraviagem", como é o caso do comerciante indiano Ismail Mahomed. 
primária; de Carlos, um dos residentes no Hotel, que tenta conseguir um pequeno empréstimo, e de Salim, que ensina o Al Corão às crianças.

A realizadora apresenta tais histórias com uma grande sensibilidade e respeito, porém a estrutura narrativa de Amanhecer a andar é bastante fragmentária. Na verdade, a obra aponta para problemáticas de vário tipo (urbanísticas, sociais, económicas, de saúde etc.), que interessam não apenas ao hotel, mas a toda a nação, sem conseguir todavia formular um olhar que envolva o espectador. Apesar disso, interessa-nos mencionar tal documentário no âmbito da nossa análise para demonstrar que a mesma temática, nesse caso a representação do Grande Hotel, pode oferecer pontos de vista muito diferentes e sugerir reflexões de carácter social, económico, cultural etc., através de narrativas e opções cinematográficas por vezes muito distintas.

$\mathrm{Na}$ realidade, tendo em conta sobretudo os três primeiros documentários mencionados, produzidos em países diferentes (Bélgica, Portugal e Moçambique), verificamos que, apesar de terem sido realizados no mesmo período (entre 2007 e 2012), são bastante diferentes no seu conteúdo. Alguns desses documentários podem abrir o debate para a análise das dinâmicas culturais e históricas geradas no espaço do Î́ndico, especificamente no caso da cidade da Beira, ao relacionar a presença do hotel com o meio envolvente. Nesse sentido, pensamos que a análise do ciclo de cinema sobre o Grande Hotel pode ajudar-nos a repensar algumas das questões identitárias e culturais relativas a Moçambique na sua relação com o Oceano Índico, nomeadamente através das interligações criadas pelo comércio, migrações e deslocamento de pessoas. Para além disso, não esqueçamos que a cidade da Beira pode ser vista como uma ilha dentro do país, devido ao seu afastamento geográfico da capital, assim como o Grande Hotel localizado na Ponta Gea pode ser considerado uma "ilha" dentro da ilha.

Seessas narrativas cinematográficas, constituídas por micronarrativas, não estão propriamente centradas no espaço movediço das águas do Oceano Índico, todavia permitem repensar a importância dessa cidade portuária, inserindo-a nas redes de comércio e de migrações que atravessa(ra)m o oceano. Assim, é possível entender de que forma essa cidade esteve (e está) em contacto com o oceano não só de um ponto de vista comercial, mas também humano, ${ }^{23}$ como demostram, por exemplo,

23 Retomamos a expressão "human ocean" (MOORTHY; JAMAL, 2010, p. 14). 
as histórias de alguns dos entrevistados no documentário de Anabela Saint-Maurice.

Esse documentário alcança tal objectivo mudando a perspectiva a partir da qual acompanha os processos migratórios que cruzam o espaço do oceano e que interessam ao litoral moçambicano. A realizadora portuguesa não foca apenas a perspectiva dos retornados, como é o caso de Lotte Stoops através da protagonista Berta, mas alarga esse olhar para a China e para a Índia. O ponto de vista da obra de Anabela de Saint-Maurice enquadra-se assim na perspectiva de Vergès (apud MUECKE, 2010, p. 42), o qual afirma que: "Our project is now decentering the gaze and redrawing the cartography of the world from the Indian Ocean view-point, here where France, Africa, Europe, Asia and Muslim worlds cross paths". ${ }^{24}$ Note-se também que as novas dinâmicas religiosas, nomeadamente no que dizem respeito ao islamismo, favorecem um renovado elo transnacional. Pensemos por exemplo no projecto de realojamento (promovido pela Associação muçulmana de Sofala e financiado por Dubai) de parte dos habitantes muçulmanos do hotel.

Para além disso, tendo em conta a representação do Índico nesses documentários, verificamos que o oceano se apresenta como pano de fundo: é uma fotografia colonial olhada com melancolia na obra de Lotte Stoops; uma abertura para um futuro melhor no documentário de Licínio Azevedo, através da emblemática imagem das crianças a olharem para a vastidão do oceano na varanda do Grande Hotel; e, por último, uma fonte de riqueza comercial e uma rede de ligação com o Oriente na obra de Anabela de Saint-Maurice.

Nesse último documentário a realizadora evidencia também um dos problemas recorrentes da Beira: as cheias. As frequentes inundações têm a ver em parte com a conformação geográfica dessa zona dominada por pântanos. Note-se a esse propósito que a cidade surgiu num território arenoso e lamacento, que foi gradualmente bonificado; para além disso, é importante ter em conta que ela está localizada numa posição geográfica liminal entre o mar e os rios Pungué, Búzi e Chiveve. Como confirmam os autores de "Beira, uma paisagem modernista na África Tropical" (FERNANDES; MEALHA; MENDES, 2016, p. 78),

24 "O nosso projecto está decentrando a atenção e redesenhando a cartografia do mundo a partir do ponto de vista do Oceano Índico, onde se cruzam a França, a África, a Europa, a Ásia e os mundos Muçulmanos." 
a localização para a constituição de uma colónia não era a mais indicada, pois as cheias dos rios limítrofes e as marés vivas do Índico inundavam a povoação. Essa situação recorrente era agravada pelo suporte arenoso no qual assentavam as construções do povoado [...].

Essa zona do litoral é descrita por Antonio Sopa (apud FERNANDES; MEALHA; MENDES, 2016, p. 78) como um "enorme lameiro líquido, gerador de humidades e pestilências, permanentemente ameaçada pelas marés e temporais".

Tendo em conta a posiçãogeográfica da cidadee dos bairros localizados entre o rio e o oceano, bem como essa consistência semilíquida, fluida e lamacenta do território beirense, considere-se o primeiro capítulo do livro Ponta Gea, titulado "Cidade líquida" (COELHO, 2017, pp. 13-30).

Ponta Gea, de JPBC, pode ser considerado uma recolha de breves capítulos que evocam as memórias da infância e juventude do autor, ligadas à cartografia da cidade da Beira. Através das lembranças do narrador, o texto foca ora determinados locais da cidade, ora a vivência de alguns dos habitantes ou visitantes que se cruzaram ali. Então, nesse texto, a geografia urbana da cidade coabita com a infância, outro país perdido que é relembrado por meio da ficção narrativa.

No primeiro capítulo do livro, "Cidade líquida”, o narrador descreve a experiência das cheias nessa zona do litoral, sendo que a evocação da inundação relembra também o final do anterior livro do autor, Água: uma novela rural (2016), criando assim uma espécie de continuidade entre o elemento líquido presente nas duas obras. A ausência de água, tema predominante no livro publicado em 2016, deixa lugar à "Cidade líquida", demonstrando a paradoxal situação moçambicana, onde as secas e as cheias alternam-se dramaticamente ou até acontecem ao mesmo tempo em diferentes pontos do país.

No incipit de "Cidade líquida", o autor centra a atenção no elemento aquático: "É a primeira e mais persistente lembrança: a água como substância da cidade" (COELHO, 2017, p. 13). À imagem da água quieta, insidiosa ou avassaladora, segue outro elemento paisagístico recorrente na cidade, o mangal, transformado em mar durante a época da chuva (p. 14). Então, há uma convergência entre a água e a cidade da Beira através “[d]os beijos gulosos que o Îndico dá à cidade" (p. 19) e tudo se mistura numa única e multiforme identidade hídrica que submerge e engloba o litoral beirense. 
Nesse capítulo o autor relata também uma série de factos dramáticos relacionados com a vida no mar dessa cidade: "a cidade inteira enchia-se de naufrágios e afogados, tantos que parecia ela própria também querer naufragar" (COELHO, 2017, pp. 26-27), retomando esse aspecto num dos fragmentos finais do capítulo:

Cidade líquida até na humidade dos corpos e das sombras, das espessas manchas sob as árvores e alpendres, das bocas negras que são estas garagens da Ponta Gea onde nos escondemos para sobreviver, [...]. É a água que triunfa. As coisas duras da cidade - as árvores, as casas e as pessoas - afundam lentamente neste nosso líquido amniótico e ganham a consistência do coral. (COELHO, 2017, pp. 28-30, grifo nosso)

O bairro de Ponta Gea converte-se então numa metonímia da cidade e do país, submersos pela água e destinados à deriva como um barco levado pelo mar. $\mathrm{O}$ discurso metafórico torna ainda mais profundo o sentido avassalador da água, no entanto sua ação é vista também como um novo nascimento, devido à propriedade de regeneração desse "líquido amniótico", que ao substituir as raízes pelo coral transforma a identidade dos seus habitantes. Note-se que a ideia de coral e da identidade coralina ${ }^{25}$ é utilizada por Khal Torabully (2008) para coadjuvar a noção de coolitude e como alternativa ao conceito identitário de rizoma. ${ }^{26}$ Leia-se a esse propósito o depoimento do poeta mauriciano:

25 Agradeço a intervenção da professora Ute Fendler (University of Bayreuth), que mencionou o conceito de identidade coralina de Khal Torabully no encontro que teve lugar em Lisboa em julho de 2017, no âmbito do Projecto NILUS-Narrativas do Oceano Índico no Espaço Lusófono, financiado pela Fundação para a Ciência e a Tecnologia. Num depoimento do poeta mauriciano, podemos ler: "la coolitude n'est ni un pavé ni une pierre, mais un corail. Une image proche, tactile, forte et fragile à la fois, que je propose comme tentative d'imaginer le monde, afin de permettre aux divers imaginaires et cultures de trouver des chemins de traverse, des cristallisations, des précipitations, et non seulement des errances" [a coolitude não é nem um chão, nem uma pedra, mas um coral. Uma imagem próxima, tátil, forte e frágil ao mesmo tempo, que proponho como uma tentativa de imaginar o mundo, para permitir que vários imaginários e culturas encontrem cruzamentos, cristalizações, precipitações e não apenas errâncias] (TORABULLY, 2008, [s.p.]).

26 A esse propósito, Khal Torabully (2016, [s.p.]) esclarece: “J’ai développé le corail comme support de la métaphore de la coolitude, car tout en étant ancré, le corail voyage sans cesse, et pour aller vite dans la comparaison, le rhizome demeure attaché, emprisonné à son terreau, où il demeure une racine à propagation horizontale" [Desenvolvi o coral como suporte para a metáfora da coolitude, porque, enquanto ancorado, o coral viaja constantemente em comparação ao rizoma, que permanece preso, aprisionado em seu solo, onde permanece uma raiz que se propaga horizontalmente]. 
Comme vous le savez, je préfère le corail au rhizome développé par Deleuze et Guattari, repris par Glissant, comme métaphore de la diversité de la créolité et de la créolisation, car le corail est ancré et mobile à la fois, revêtant diverses textures et teintes, se façonnant au gré des courants et libérant le plancton pour la plus grande migration sur terre. Donc il est déjà dans l'entre-deux idéal, ancré et mobile aux fonds des océans.

[...] De plus, le corail est dans la connectivité agglutinante, et non la connectivité errante du rhizome, seulement, car le corail peut s'agglutiner à d'autres coraux, mais aussi à d'autres matières et supports, tels des rochers, des coulées de lave, de épaves de bateaux... Donc, il quitte son espèce précise pour aller vers d'autres, ce qui n'est pas le cas du rhizome qui reste malgré tout sous terre, et rarement se fixe sur d'autres espèces. (TORABULLY, 2008, [s.p.]) $)^{27}$

Essa ideia da identidade coralina poderá ajudar-nos a repensar a presença, na cidade da Beira, de culturas orientais oriundas do "outro lado” do Índico, como emerge do documentário de Saint-Maurice e ao longo do livro de JPBC. Essas identidades se encontram e se aglomeram assim como faz o coral, segundo a explicação de Torabully (2008; 2016).

De resto, no livro de JPBC (2017) há dois capítulos que fazem referência ao diálogo cultural com o Oriente. Pensemos, por exemplo, no capítulo 7, titulado "Dona Carol", no qual é narrada a vida de uma sofisticada e erudita mulher indiana que chegou à cidade da Beira após ter casado com Dom Miguel de Paiva Couceiro, capitão da Marinha portuguesa e antigo administrador de Diu, território da antiga colónia na Índia portuguesa. A biografia ficcionada, reconstruída pelo autor, repercorre as etapas geográficas da vida de Dona Carol, filha de um homem chamado Talibud-din [aquele que procura a fé] (COELHO, 2017, p. 136), descendente de uma família muçulmana convertida ao cristianismo, desde a infância e juventude no Estado de Punjab, passando pela independência do Paquistão em 1947, depois em Bombaim, onde conheceu o futuro marido, com quem se casou no Ceilão, e finalmente na cidade da Beira, para onde

27 "Como sabe, eu prefiro o Coral ao Rizoma desenvolvido por Deleuze e Guattari e retomado por Glissant, como uma metáfora para a diversidade da crioulidade e da creolização, porque o coral é ancorado e móvel ao mesmo tempo, apresentando várias texturas e matizes, moldando-se de acordo com as correntes e liberando o plâncton para uma maior migração em terra. Por isso, já está nos fundos oceânicos idealmente ancorado e móvel. [...] Além disso, o coral tem uma conectividade aglutinante, e não uma conectividade errante, como a do rizoma, porque o coral se pode unir a outros corais, mas também a outros materiais e suportes, como as rochas, os fluxos de lava, os navios naufragados... Então, deixa a sua espécie para ir ao encontro dos outros, o que não é o caso do rizoma, que permanece, apesar de tudo, no subsolo e raramente se liga a outras espécies." 
se transferiu o casal. Nesse roteiro geográfico um dos aspectos que nos interessa evidenciar é a presença de uma "dimensão material das culturas do Índico" (FALCONI, 2013, p. 88), ligadas, nesse caso, ao mundo oriental. Pensemos, por exemplo, no mundo que envolve Dona Carol: os cães chow chow, os elegantes saris, o choli, ${ }^{28}$ o bindi ${ }^{29}$ luminoso na cara, o precioso livro com a capa escrita em urdu, todos esses elementos contribuem para tornar Dona Carol numa deusa, a Khali da casa beirense.

Em outros capítulos do livro, é recorrente também a presença de chineses, como é o caso do capítulo 11, "Dragão Oriental (Mercearia \& Brindes)" (COELHO, 2017), no qual prevalece uma detalhadíssima descrição de vários elementos materiais e olfativos que caracterizam a loja chinesa de Yue Huang Shee. A propósito do aspecto material ligado ao mundo oriental, sobretudo chinês e indiano, como vimos, também o documentário de Anabela de Saint-Maurice penetra no mundo das lojas e mercearias chineses e indianas da cidade da Beira, através de um olhar que, a partir do Grande Hotel, se estende ao seu envolvente.

O Grande Hotel é também o protagonista silencioso do livro de JPBC; na verdade, no romance Ponta Gea não podia faltar um capítulo dedicado ao hotel localizado no homónimo bairro. A propósito desse capítulo, podemos compará-lo à construção narrativa do documentário de Licínio Azevedo (HÓSPEDES, 2007). Referimo-nos, no específico, à sobreposição de dois períodos cronológicos e a uma estranha "convivência" entre os protagonistas do passado e os do presente. Para compreendermos melhor esse aspecto, iremos recorrer a alguns trechos do capítulo sobre o Grande Hotel.

Se no documentário de Azevedo os dois ex-empregados que evocam o passado circulam na actual estrutura do hotel, relembrando um mundo que já não existe, no texto de JPBC o espaço do hotel é partilhado pela presença simultânea das crianças do passado (incluindo o narrador) e das crianças do futuro (ou seja, os actuais moradores). Assim, o hotel ganha a dimensão de uma aeronave futurista:

Foi preciso muito tempo, inúmeros voos da grande nave trespassando anos, para que descobríssemos que quem nos espreitava eram afinal bandos de crianças do futuro, sorridentes e barrigudas, de pés descalços e calções esfarrapados, o nariz sempre pingando. [...] crianças que no futuro o habitariam sem o ter escolhido, sem ter ludibriado o ogre para nele entrar, sem ter uma bicicleta para

28 Blusa curta, tradicionalmente utilizada com o sari.

29 Decoração colocada na testa (entre os olhos) pelas mulheres indianas. 
o percorrer. Crianças que por enquanto não víamos, crianças que mesmo no futuro persistiriam na sua transparência. (COELHO, 2017, pp. 122-123, grifos nossos)

A propósito do trecho final, note-se que a descrição da transparência das crianças do futuro (ou seja, do actual presente) relembra curiosamente o apagamento social (e físico) do indivíduo no romance Os transparentes do escritorangolano Ondjaki (2012). Para além disso, verificamosque no Grande Hotel há uma estranha suspensão temporal, porque as fantasmagóricas figuras evocadas pelo narrador não são apenas as crianças do futuro, mas também as do passado (incluindo o narrador). Na realidade, as crianças que povoam a infância do narrador são elas próprias fantasmas: "nós próprios jovens ciclistas-fantasmas chegados do passado para assombrar os novos habitantes destes quartos" (COELHO, 2017, p. 128).

Então, verificamos que nesse capítulo a sobreposição de diferentes tempos cronológicos estabelece uma correspondência espacial entre a vida quotidiana dos moradores do hotel, tão bem retratada no documentário de Licínio Azevedo (HÓSPEDES, 2007), com as corridas daquelas crianças do passado (entre as quais se inclui o narrador), evocadas no conto de Ponta Gea (2017). Assim, o narrador do presente pós-colonial, através da artimanha literária, faz conviver no espaço do Grande Hotel as crianças do passado e as do futuro.

Para além disso, existe uma correspondência por assim dizer "intraliterária” entre a descrição do hotel no livro Ponta Gea (2017) e o conto "Casas de ferro", de Índicos indícios I - Setentrião (2005), ambos de JBPC. Na verdade, o narrador de Ponta Gea evoca enigmaticamente o quarto 302 (COELHO, 2017, p. 128), o mesmo quarto que já deu nome a um protagonista, também ele uma criança, do conto "Casas de ferro", o menino 302, como a querer confirmar que na literatura a realidade e a ficção se fundem e refundem constantemente.

Por último, comparando o capítulo sobre o Grande Hotel (COELHO, 2017) com o documentário de Azevedo (HÓSPEDES, 2007), verificamos que a descrição do ambiente requintado do hotel com os quadros, as luxuosas ornamentações e o mobiliário, os longos corredores etc. corresponde às imagens evocadas verbalmente pelos dois ex-empregados no documentário. Todavia, o espaço evocado no capítulo de Ponta Gea já apresenta algum sinal da iminente decadência (repare-se que a estrutura é quase deserta, à excepção do guarda-ogre), pelo facto de o hotel já não funcionar 
normalmente nesse período, visto que abria suas portas apenas em ocasião de grandes eventos organizados para a alta sociedade beirense (e não só).

Notamos também que, como emerge nos documentários analisados, os moradores do hotel foram vendendo, ao longo do tempo, elementos ornamentais e estruturais desse edifício, contribuindo assim para a sua destruição. Nesse sentido, como realmente aconteceu ao longo dos anos, no final do capítulo sobre o Grande Hotel (COELHO, 2017), à medida que as crianças atravessam os corredores vazios com suas bicicletas, a estrutura vai desintegrando-se. E o progressivo desaparecimento do hotel acompanha a migração das crianças do passado colonial para o futuro, "enquanto a nave implode nas nossas costas levando consigo os velhos e novos ogres deste mundo ainda e sempre insano" (p. 130). Considerando o progressivo desaparecimento e a destruição dos elementos ornamentais e estruturais do Grande Hotel, que cedem lugar ao vazio, verificamos que a desintegração do hotel pode ser vista como uma metáfora do progressivo desaparecimento da memória individual e colectiva. Com os destroços do hotel, cancela-se, no fundo, parte da memória ligada àquele lugar.

Em conclusão, podemos dizer que o Grande Hotel, enquanto objecto de representação cinematográfica e literária, problematiza a relação entre o passado colonial e o presente. Para além disso, repensando a relação do litoral moçambicano e, mais no específico, da cidade da Beira com o Oceano Índico, verificamos que o documentário de Anabela de SaintMaurice, assim como a narrativa de JPBC no livro Ponta Gea, oferecem uma imagem da cidade da Beira enquanto fruto das rotas comerciais, marítimas e migratórias que cruzaram o Oceano Índico e das quais emerge também uma variedade de culturas relacionadas sobretudo com o Oriente. Essa estrutura coralina da cidade faz com que a Beira se aproxime cada vez mais do estado líquido, uma "cidade líquida" que se junta às muitas ilhas que compõem a variegada constelação desse vasto oceano.

\section{THE CYCLE ABOUT THE GRANDE HOTEL IN BEIRA: THE DOCUMENTARIES GRANDE HOTEL, BY LOTTE STOOPS; GRANDE HOTEL, BY ANABELA SAINT-MAURICE; HÓSPEDES DA NOITE, BY LICÍNIO AZEVEDO AND AMANHECER A ANDAR, BY SÍLVIA FIRMINO}

\footnotetext{
Abstract: This article aims to analyse four documentaries about the Grande Hotel in Beira, Mozambique. In this essay we will focus on post-independence cinematographic representations of the Grande Hotel. We will analyse the perspectives that reveal the
} 
multiculturality of Beira as a result of the connections created across the Indian Ocean and we will discuss the relation between the postcolonial present and the colonial past. At the end of the text we will also mention the latest book by João Paulo Borges Coelho, Ponta Gea (2017), which refers to the neighborhood in Beira where the Grand Hotel is located. Keywords: Grande Hotel; documentaries; Indian Ocean.

\section{REFERÊNCIAS}

ALPERS, Edward. Maritime Mozambique. Tsingy, n. 18, 2015, pp. 15-34. Disponível em: <https://www.academia.edu/24855175/Maritime_Mozambique_Tsingy_18_2015_>. Acesso em: ago. 2017.

AMANHECER A andar. Direção de Sílvia Firmino. Portugal, CRIM, 2012. Documentário (97 min.).

COELHO, João Paulo Borges. Ponta Gea. Lisboa: Caminho, 2017.

COELHO, João Paulo Borges. Índicos indícios I-Setentrião:estórias. Lisboa:Caminho, 2005.

FALCONI, Jessica. Para fazer um mar. Literatura moçambicana e Oceano Índico. Diacrítica, v. 27, n. 3, 2013, pp. 77-92. Disponível em: <www.scielo.mec.pt/pdf/dia/ v27n3/v27nzao6.pdf>. Acesso em: jul. 2017.

FERNANDES, Mário Gonçalves; MEALHA, Rui Passos; MENDES, Rui Paes. Beira, uma paisagem modernista na África Tropical. Urbe. Revista Brasileira de Gestão Urbana, v. 8, n. 1, jan./abr. 2016, pp. 155-166. Disponível em: <www.scielo.br/pdf/ urbe/2015nahead/2175-3369-urbe-2175-33690o80o1AOo4.pdf>. Acesso em: jul. 2017.

GRANDE HOTEL. Direção de Anabela de Saint-Maurice. Portugal, Ana Lucas, 2007. Documentário (52 min.). Disponível em: <http://www.cultureunplugged.com/ documentary/watch-online/play/7430/Grande-Hotel>. Acesso em: jul. 2017.

GRANDE HOTEL. Direção de Lotte Stoops. Bélgica, Serendipity Films, 2010. Documentário (7o min.).

HÓSPEDES DA noite. Direção de Licínio Azevedo. Moçambique, Ébano Multimedia, 2007. Documentário (53 min.).

MAGALHÃES, Ana. Estação de Caminho de Ferro da Beira: apogeu e crítica do movimento moderno em Moçambique. In: Atas do Congresso Internacional Saber Tropical em Moçambique: História, Memória e Ciência. IICT-JBT/Jardim Botânico Tropical, Lisboa, 2012. Disponível em: <ewv.ist.utl.pt/PDF/AM_Saber\%2oTropical.pdf>. Acesso em: jul. 2017.

MAGALHÃES, Ana. Moderno Tropical: arquitectura em Angola e Moçambique 1948-1975. Fotografia de Inês Gonçalves. Lisboa: Tinta de China, 2009. 
MALOA, Joaquim Miranda. A urbanização moçambicana. Uma proposta de interpretação. Tese de doutorado em Geografia Humana) - Faculdade de Filosofia, Letras e Ciências Humanas, USP, São Paulo, 2016. Disponível em: <www.teses.usp.br/teses/ disponiveis/8/8136/tde-05082016-155420/>. Acesso em: jul. 2017.

MEDEIROS, Eduardo. Etnia e raça no desporto beirense da época colonial. O caso dos "sino-moçambicanos". Cadernos de Estudos Africanos [on-line], n. 26, 2013, pp. 4581. Disponível em: <http://cea.revues.org/1115>. Acesso em: jul. 2017.

MEDEIROS, Eduardo. Os sino-moçambicanos da Beira. Mestiçagens várias. Cadernos de Estudos Africanos [on-line], n. 13/14, 2007, pp. 1-23. Disponível em: <https://cea. revues.org/494>. Acesso em: jul. 2017.

MOÇAMBIQUE - DO outro lado do tempo. Direção de Luís Beja. Portugal, Beja Filmes, 1996. Documentário (71 min.).

MOORTHY, Shanti. Abdulrazak Gurnah and Littoral Cosmopolitanism. In: MOORTHY, Shanti; JAMAL, Ashraf (Orgs.). Indian Ocean Studies. Cultural, Social and Political Perspectives. Londres / Nova York: Routledge, 2010, pp. 73-102.

MOORTHY, Shanti; JAMAL, Ashraf. Introduction: New Conjunctures in Maritime Imaginaries. In: MOORTHY, Shanti; JAMAL, Ashraf (Orgs.). Indian Ocean Studies. Cultural, Social and Political Perspectives. Londres/Nova York: Routledge, 2010, pp. 1- 31.

MUECKE, Stephen. Fabulation: Flying Carpets and Artful Politics in the Indian Ocean. In: MOORTHY, Shanti; JAMAL, Ashraf (Orgs.). Indian Ocean Studies. Cultural, Social and Political Perspectives. Londres/Nova York: Routledge, 2010, pp. 32-44.

STOOPS, Lotte. Director's statements. Grande Hotel. S.d. Disponível em: <http:// grandehotelthemovie.com/\#/about/director\%27s\%2ostatement>. Acesso em: ago. 2017.

TORABULLY, Khal. Ce que la Coolitude propose dans son acte de naissance: une voix de la diversité qui n’appauvrit pas l'autre à l'aune de sa propre définition de la diversité. IndesRéunionnaises, jun. 2008. Disponível em: <http://www.indereunion.net/actu/ khal/interKhal.htm>. Acesso em: ago. 2017.

TORABULLY, Khal. [Entrevista a Pierre Carpienter]. Le Poète Mauricien a l'origine de la coolitude évoque Éduard Glissant. Montray Kréyol, set. 2016. Disponível em: <http://www.montraykreyol.org/article/khal-torabully-le-poete-mauricien-alorigine-de-la-coolitude-evoque-edouard-glissant>. Acesso em: ago. 2017. 